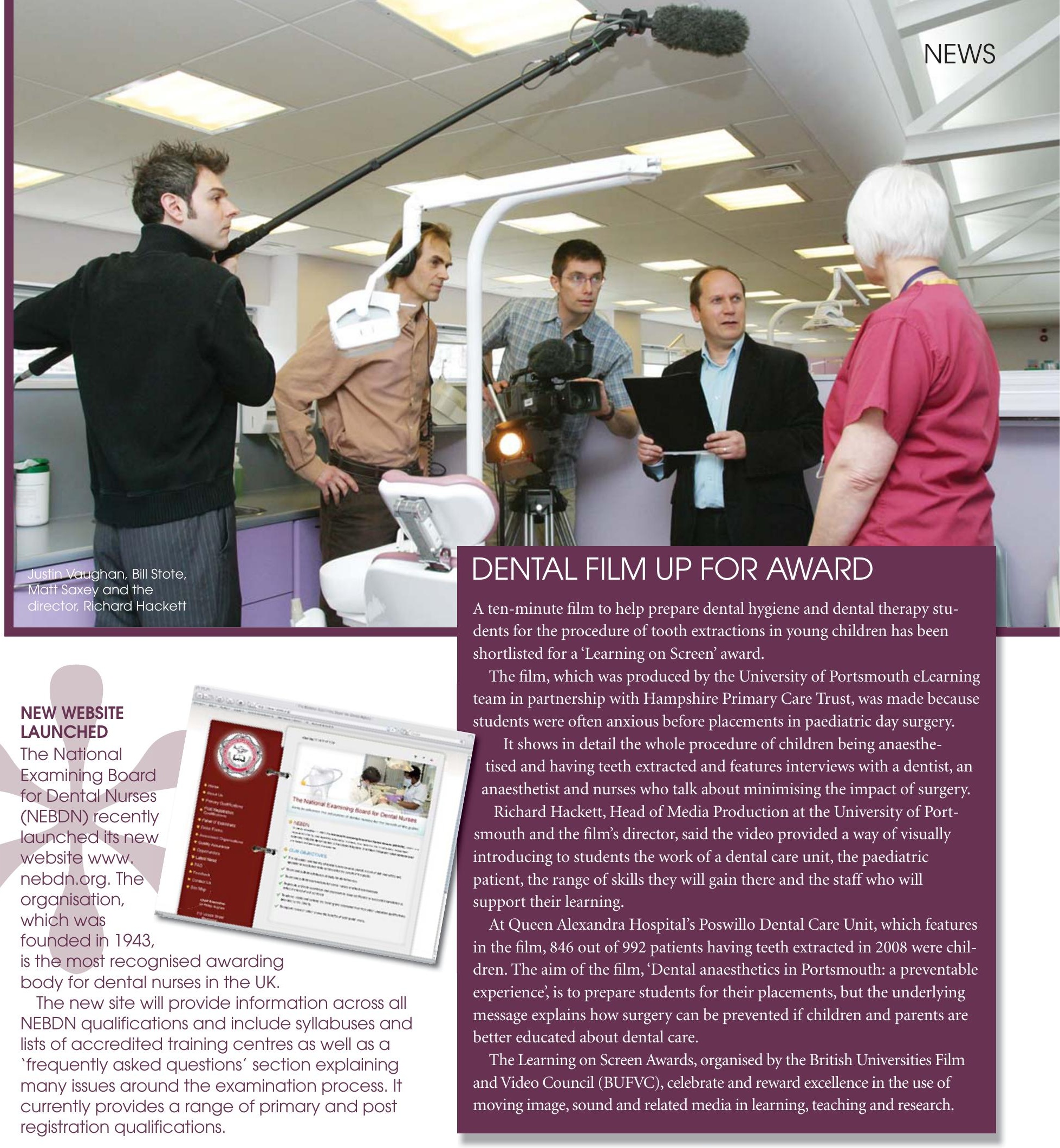

\title{
TAKING A BREAK TO HELP
}

For two weeks a year, dentist Liz Stringer of Village Dental Practice in Knebworth, shuts up shop to volunteer her time and skills in rural Tanzania. Together with her dental nurses, Su Mills and Tracey Evans, she is part of Bridge2Aid's Dental Volunteer Programme (DVP).

The many volunteers pass on their dental skills to rural Clinical Officers that lack basic dental training and Liz, Tracey and Su have made a long-term difference to the lives of many of the poorest Tanzanians by giving their time and efforts to train indigenous people, transferring their skills in the most effective way.

This is something very close to the heart of the Bridge2Aid team, and the 100+ volunteers that work with them each year. Dental Director and Founder Ian Wilson said, 'Many people can and do take time away from their practice to make a difference - some even do so on an annual basis - and in the course of it have a great time, build their teams and help enhance their reputation with patients.'

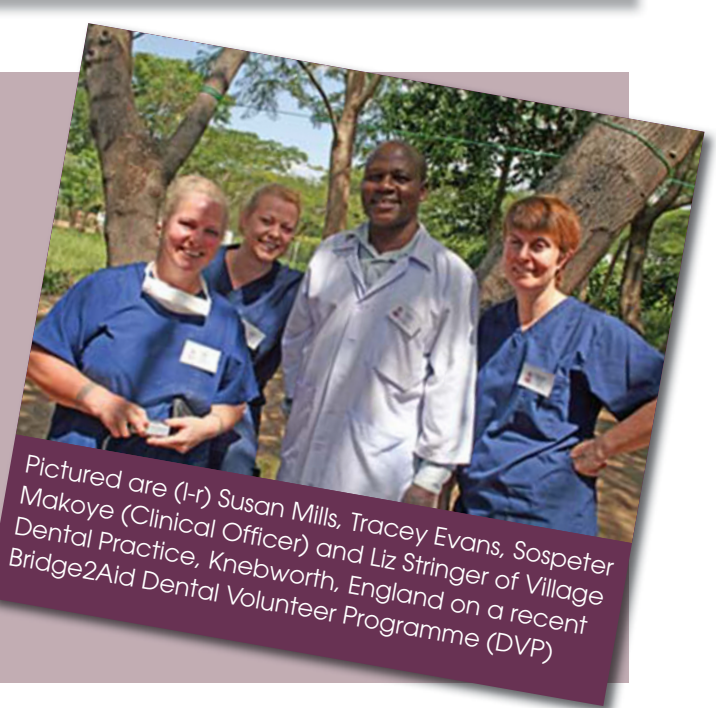

vital 11 